\section{Editorial 21/1}

\section{Hubert Österle • Hans-Dieter Zimmermann • Rainer Alt}

Published online: 10 March 2011

(C) Institute of Information Management, University of St. Gallen 2011

Dear Readers of Electronic Markets,

"We are happy, if we were able to spark or deepen your interest in electronic markets ...". This was the message of the editorial of the first issue of Electronic Markets, back in September 1991 when "EM" started as a newsletter. Justin-time for its 20th anniversary the journal has been selected by Thomson Reuters for the Social Sciences Citation Index, the Journal Citations Report, and Current Contents.

The vision of almost perfect markets based on the capabilities of the upcoming Internet motivated Beat Schmid and his team at the Competence Center Electronic Markets at the University of St. Gallen to create a publication platform for researchers and practitioners. Together with several leading researchers, such as Thomas Malone and Rolf Wigand (see interview on pp. 5 - 20 of Volume 21 Number 1) they shared the vision of highly efficient market mechanisms as a new and possibly dominant coordination mechanism in the internet economy which was about to emerge in the industry. Practically at the same time hundreds of start-ups tried to make use of the electronic market

\author{
H. Österle $(\bowtie)$ \\ University of St. Gallen, \\ St. Gallen, Switzerland \\ e-mail: hubert.oesterle@unisg.ch \\ H.-D. Zimmermann \\ University of Applied Sciences, FHS St. Gallen, \\ St. Gallen, Switzerland \\ e-mail: hansdieter.zimmermann@fhsg.ch \\ R. Alt \\ University of Leipzig, \\ Leipzig, Germany \\ e-mail: rainer.alt@uni-leipzig.de
}

concept and, according to Singh (Singh 2004), created more than 12,000 markets such as eBay for consumers as well as Covisint for the automotive industry on the Internet.

Electronic markets rely on some fundamental concepts. The first is free access to the market for all, for individuals as well as for businesses, in their role as producers and as consumers. Openness instead of power from the big players, democracy instead of autocracy was and partly still is one of the long-term goals. A fundamental part of free access is a high level of transparency.

Based on standardization electronic markets give the consumer comprehensive information regarding all kinds of relevant offerings - services as well as products. In addition they provide producers with a wealth of information on the consumers and their needs.

Globalization is another basis for the new economy. In the words of Thomas Friedman's "The World is Flat" (Friedman 2004), the boundaries of countries and continents have lost their influence on doing business. That enables the availability of information independent of the actual location, the global sourcing of products and to a certain degree of services, as well as the outsourcing of business functions to specialized service providers. People and businesses need to become much more flexible to adapt to new opportunities worldwide. Electronic markets can disassemble well-established hierarchies and substitute them by an ad-hoc collaboration of market players (Malone 2004). Information technology has radically reduced transaction costs in many industries. The best example is the electronic trading of financial instruments where the fees of exchanges and banks tumbled to a tenth or hundredth of their price 15 years ago. In addition extensive research has emerged in the area of auctioning and pricing mechanisms which have also changed collaboration in several industries. 
Already in the 1960s with Peter Mertens' book on interorganizational communication and cooperation (Mertens 1966) we could identify a second stream of IT-enabled reorganization of collaboration. Electronic Data Interchange (EDI), Enterprise Resource Planning (ERP), Supply Chain Management (SCM), and related terms describe a dominant development in restructuring all industries and enterprises. In contrast to the market paradigm they concentrated on the business process view, enterprise internal processes in the beginning and inter organizational processes in the last 20 years. In many cases this typically hierarchical collaboration had an even bigger impact on the economies than the pure market approach. Establishing business relationships for a long duration and a large number of transactions these inter-organizational processes enabled global sourcing, low transaction costs, dramatically reduced cycle times, and more efficient planning due to increased transparency.

Rolf Wigand, Arnold Picot and Ralf Reichwald (Wigand et al. 1997) integrated developments, the electronic markets evolution and the extended business process redesign in their book "Information, Organization and Management: Expanding Markets and Corporate Boundaries." Another perspective that emerged from linking internal ERPsystems was Business Networking comprising application areas, such as SCM, Customer Relationship Management and Electronic Commerce as well as organizational implications, such as interorganizational collaboration, (dis) intermediation, outsourcing and out-tasking (Österle et al. 2001).

Not all of the collaboration concepts worked out the way scientists and practitioners expected. Therefore, about $90 \%$ of the electronic markets of the 1990s disappeared with the downturn of e-business shortly after the year 2000. Some industry structures became rather monopolistic than open or democratic. Search engines, social networks, smart phones, localization and navigation, and some other areas give evidence of that development. However, Wikipedia is a good example of democratizing knowledge and its representation in collective intelligence.

These new fields of networking via the Internet expand the scope of research covered by our journal expressed in the subtitle by "The International Journal on Networked Business". Electronic Markets does not focus on simply one collaboration mechanism in the value chain, but it is open to all contributions understanding and innovating the diverse fields of communication and collaboration among individuals, enterprises, governmental organizations, and even things (real world connection). It is not restricted to structured information as used in enterprise management systems but also encompasses all kinds of knowledge.

An important research question for the coming years could be how we are going to master the rapidly growing complexity. This could lead us to a detailed analysis of the individual and our view of the diversity of systems and the design of solutions to reduce this complexity.

If we take a self-critical view on the role of science, the information systems research community, we should ask: What could our discipline contribute to the development of an industry that has apparently changed and is still changing the world? Could researchers, teachers, and journals such as Electronic Markets help to understand the opportunities and threats? Could they deliver innovative concepts and solutions? Do success stories like Google, Facebook, Twitter, SAP, or Wikipedia have their origin in our discipline?

Scientific publications in this and similar journals should inspire young researchers and students at universities and motivate them to engage themselves in the promising opportunities in this area. In many cases the articles published in Electronic Markets should have opened new views on market phenomena and given some advice for the design of instantiations of collaboration mechanisms. The struggle of information systems research for accuracy has had a serious impact on the relevance of publications, not just in our journal. This becomes obvious if one compares the articles of the first issues of "Electronic Markets" and the most recent volumes. Thus, one of the goals of the editorial board is to further strengthen the relevance and practical impact without sacrificing scientific quality. The current discussion of research methods in the scientific community and the strengthening of the design science research provide support in that endeavor.

We are aware that many colleagues share this view and that the journal Electronic Markets would not have experienced such a successful development during the past 20 years without the support of all its contributors, be it as authors, reviewers, editorial board members or associate editors. We are indebted to all who have helped to make Electronic Markets what it is today-an international premier SSCI-listed journal for research in value chain collaboration. In view of this development this issue of Electronic Markets presents three special theme articles on "20 Years Research in Electronic Markets and Networked Business" and two general research papers.

We are pleased to present you an interview with Tom Malone reflecting on the classic paper, "Electronic Markets and Electronic Hierarchies" with JoAnne Yates and Bob Benjamin appearing 23 years ago, i.e. 1987, in the Communications of the ACM. It established the concept of the Electronic Market Hypothesis (EMH) that has considerably impacted our field. This seminal piece has been cited 2,447 times in the literature according to Google Scholar and it has triggered numerous streams of and helped discover novel directions for research. Rolf Wigand conducted the interview with Tom Malone on July 14, 2010 at 
MIT and asks if the EMH has withstood the test of time and other questions. We are also very pleased that JoAnne Yates and Bob Benjamin offer their own retrospectives on this landmark paper on electronic markets and electronic hierarchies. Moreover, we are delighted to bring you this interview, a most fitting feature, for our 20th anniversary issue of $E M$.

The invited paper "Co-Authorship Networks in Electronic Markets Research - an exploratory study", authored by Kai Fischbach, Johannes Putzke and Detlef Schoder, analyzes the co-authorships of articles in Electronic Markets and provides descriptive statistics regarding the degree to which researchers are embedded in the co-authorship network. Seven hypotheses associating the researchers' embeddedness in the co-authorship network with the number of the researchers' citations were developed and tested. The results give detailed insights into citation frequency depending on co-authorship based on data of papers published in 20 volumes of Electronic Markets.

A position paper by Rainer Alt and Stefan Klein takes the 'Electronic markets and hierarchies' classic as a starting point to illustrate how electronic markets have emerged over the past 20 years and present their thoughts on future developments. It turns out that the concept of electronic markets is far from being focused on the allocation of resources among multiple participants based on market mechanisms. Moreover, Electronic Markets have become a key enabler for interorganizational collaboration and will maintain an important role in the future. However, this requires the careful identification of the value added by these intermediaries and the consideration of multiple risks that are also included in the electronic markets concept.

The first general research paper "A Virtual Competition Auction Model for Perishable Products" was authored by Shouhong Wang and Hai Wang and addresses online auctions proposing a virtual competition auction model for perishable products. Results of the preliminary laboratory experiment show that the virtual competition auction model for perishable products is more effective than the ordinary open outcry auction model.
Philipp Menschner, Andreas Prinz; Philip Koene, Felix Köbler, Matthias Altmann; Helmut Krcmar, and Jan Marco Leimeister address the area of Ambient Assisted Living (AAL) in their paper "Reaching into patients' homesparticipatory designed AAL services". The research proposes a novel approach for engineering AAL services (AALSDA) combining methods from service engineering and participatory design. The authors report and discuss the results of the approach's test in a pilot study.

We hope you enjoy reading this jubilee issue of Electronic Markets and hope that you all continue to support Electronic Markets in the future. We look forward to working together with all of you and would be happy about any feedback on the journal or single contributions. Lastly, we hope you join us in celebrating the 20th anniversary of Electronic Markets.

Best regards,

Hubert Österle

Hans-Dieter Zimmermann

Rainer Alt

\section{References}

Friedman, T.L. (2004). The world is flat: a brief history of the twentyfirst century. New York: Farrar, Straus and Giroux

Malone, T. (2004). The future of work: How the new order of business will shape your organization, your management style, and your life. In: Harvard Business School Press.

Malone, T. W., Yates, J. \& Benjamin, R. I. (1987). Electronic markets and electronic hierarchies. In: Communications of the ACM, 1987, 30 (6), pp. 484-497.

Mertens, P. (1966). Die zwischenbetriebliche Kooperation und Integration bei der automatisierten Datenverarbeitung, Meisenheim am Glan, Hain.

Österle, H., Fleisch, E., \& Alt, R. (2001). Business networking: Shaping collaboration between enterprises. Berlin: Springer.

Singh, V. (2004). E-Marketplace Development. http://www.emarket services.com/clubs/ems/prod/eMP\%20development.pdf

Wigand, R. T., Picot, A., \& Reichwald, R. (1997). Information, organization and management: Expanding Markets and corporate boundaries. Chichester: Wiley. 